\title{
ARTICLE REVIEW - POTENSI GAME EDUKASI DALAM UPAYA PELESTARIAN BATIK INDONESIA
}

\author{
Novan Edo Pratama \\ Institut Teknologi Bandung \\ E-mail: novanedo@students.itb.ac.id
}

\begin{tabular}{ll}
\hline ARTICLE INFO & ABSTRAK \\
\hline $\begin{array}{l}\text { Article history: } \\
\text { Received: } 10 \text { September } 2019 \\
\text { Revised: } 17 \text { September 2019 } \\
\text { Accepted: 21 September 2019 }\end{array}$ & $\begin{array}{l}\text { Educational game has potential in transferring knowledge. } \\
\text { educational game makes it easy to deliver knowledge to students. } \text { one } \\
\text { of the elements in the game, namely character, has a role in }\end{array}$ \\
\hline $\begin{array}{l}\text { Keywords: } \\
\text { Educational Game } \\
\text { Learning Process } \\
\text { Batik Indonesia }\end{array}$ & $\begin{array}{l}\text { when it used in batik preservation. where batik is very diverse and it } \\
\text { is not easy to learn the meaning and philosophy in it. the meaning } \\
\text { and philosophy of batik in Indonesia deserves to be introduced to our } \\
\text { next generation. with a learning process that is full of culture. This } \\
\text { article discusses the potential of educational games in the learning } \\
\text { process of preserving batik culture in Indonesia. }\end{array}$
\end{tabular}

\section{PENDAHULUAN}

Game edukasi merupakan media pendidikan yang banyak digunakan untuk mentransfer ilmu, dengan visualisasi yang menarik, materi yang bisa kompleks, dengan cara yang menyenangkan, sehingga masyarakat luas dengan mudah mengetahui informasi yang ingin disampaikan. Dalam beberapa artikel sebelumnya sudah ada yang membahas tentang potensi game edukasi untuk media pembelajaran dengan tema-tema yang berbeda. Untuk kali ini penulis berupaya menyampaikan informasi Potensi Game Edukasi Dalam Upaya Pelestarian Batik Indonesia dengan sumber acuan dan referensi teori-teori dari berbagai sumber. Dari hasil kuesioner yang disebar penulis (https://bit.ly/36FvGku) survei dengan 75 Responden pelajar SMP di Yogyakarta, mendapatkan hasil 96\% remaja dengan usia 12-17 tahun tertarik dengan Batik. Sebanyak $66.7 \%$ mengerti tentang batik Keraton tetapi $45.3 \%$ ragu-ragu akan makna yang terkandung di dalam batik Keraton. Hanya sebesar $26.7 \%$ yang mengetahui makna batik Keraton. Sedangkan hasil wawancara penulis dengan seoarang abdi dalem bahwa pengunjung Keraton paling banyak didominasi oleh pelajar. Hal tersebut membuat sebuah permasalahan 
yang bisa dikaji lebih jauh tentang pelestarian kebudayaan terkait batik bagi para pelajar. Salah satu jurnal yang digunakan untuk acuan penulis adalah Jurnal Angkasa dengan judul artikel Penerapan Edugame Interaktif untuk pengenalan pakaian adat nasional Indonesia yang ditulis oleh: Dwi Nugraheny ${ }^{1}$ dan Ayuningtias Destiranti ${ }^{2}$. Kesimpulan dalam artikel tersebut: (1) Edugame interaktif pengenalan pakaian adat nasional Indonesia dapat digunakan untuk belajar sekaligus bermain dalam mengenal ciri, motif serta bentuk jenis-jenis pakain adat Nasional Indonesia. (2) Berdasarkan hasil kuesioner yang diperoleh bahwa Edugame interaktif pengenalan pakaian adat nasional telah cukup memenuhi kriteria dapat digunakan (usability), keakuratan (accuracy), relevan (relevance), kesesuaian (appropriateness), objektifitas (objectives), umpan balik (feedback). (3) Hasil yang diperoleh dari pengujian para pengguna dan menggunakan kuisoner kemudian dihitung dengan metode Likert adalah 74,1\%, maka dapat disimpulkan bahwa aplikasi edugame interaktif pengenalan pengetahuan pakaian adat Nasional Indonesia masuk ke kriteria baik.

Berdasarkan hasil yang dicapai dari jurnal Penerapan Edugame Interaktif untuk pengenalan pakaian adat nasional Indonesia penulis berusaha mengkaji kembali dengan teoriteori literatur yang sudah ada, apakah potensi game edukasi bisa digunakan dalam upaya pelestarian batik di Indonesia.

\section{METODOLOGI}

\subsection{Kajian Teori}

\subsubsection{Teori Konsep Game}

Salah satu kelebihan utama game edukasi adalah pada visualisasi dari permasalahan nyata. Massachussets Insitute of Technology (MIT) berhasil membuktikan bahwa game sangat berguna untuk meningkatkan logika dan pemahaman pemain terhadap suatumasalah melalui proyek game yang dinamai Scratch. Scratch adalah sebuah bahasa pemrograman visual untuk lingkungan pembelajaran yang memungkinkan pemula (entah murid, guru, pelajar, atau orangtua) untuk belajar membuat program tanpa harus memikirkan salah-benar penulisan sintaksis (Clark, 2006)

Sedangkan Konsep game menurut (Rolling, 2004) adalah acuan, yang pernyataannya akan selalu menjadi referensi pada saat desain. Ada dua tahapan mendefinisikan konsep game, yakni having idea dan shaping the idea.

\section{a. Having Idea}

Tahap having idea meliputi (a) Inspirasi, yakni mencari dan mengembangkan ide. (b) Sintesis yakni mengkompilasi sebaran ide menjadi ide yang original. (c) Resonansi, adalah suatu 
brainstorming membangun sinergi dari komponen game yang lain. (d) Sinergi, yakni memilih alternatif yang paling optimal untuk dibawa ke tahap berikutnya.

\section{b. Shaping The Idea}

Tahap shaping the idea adalah mengungkapkan ide dasar ke dalam 6 komponen, yakni style, theme, backstory, plot, character, dan setting.

(1) Style

Sebuah genre atau kombinasi genre yang digunakan dalam merancang game. (Rolling, 2004) menyebutkan 7 klasifikasi genre game, namun itu belum mencakup semua genre yang pernah ada, yakni action, adventure, strategy, simulation, puzzle, toys, dan education.

(2) Theme

Suatu ide filosofis dari game. Tema akan memberikan ruh atau inside feeling bagi pemain dalam bermain.

(3) Plot

Suatu rangkaian kejadian yang membangun story. Dalam setiap kejadian biasanya melibatkan pelaku, kata kerja yang dilakukan, benda-benda terlibat, dan tempat terjadinya.

(4) Backstory

Suatu cerita dibalik kejadian yang menjadi dasar acuan untuk membuat game, dapat mempengaruhi pemain dan budaya yang terjadi.

\section{(5) Character}

Karakter yang didefinisikan di konsep desain adalah karakter dari player. Sedangkan bagi desainer karakter berfungsi untuk memperkuat story.

(6) Setting

Dalam film setting mendefinisikan tentang latar tempat, latar waktu, latar lingkungan, latar suasana, termasuk siapa orang-orang yang tinggal pada latar tersebut.

\subsubsection{Teori Game Edukasi}

Game edukasi termasuk style dalam genre atau kombinasi genre yang digunakan untuk merancang game. Menurut Prensky (2012), game edukasi adalah game yang didesain untuk proses belajar, tapi tetap bisa menawarkan bermain dan bersenang-senang. Sehingga Game edukasi adalah gabungan dari konten edukasi, prinsip pembelajaran yang menciptakan proses belajar kepada pemain game.

Elemen dasar game menurut Dillon (2009) terdapat; Grafis, teks, dan suara: game biasanya merupakan kombinasi dari media teks, grafik maupun suara, walaupun tidak harus 
semuanya ada dalam permainan game dan animasi: animasi ini selalu melekat pada dunia game, khususnya untuk gerakan karakter yang ada dalam game, dan properti dari objek.

\subsubsection{Teori Karakter Game}

Karakter dalam game tidak bisa jauh dari sebuah definisi ilustrasi. Ilustrasi dapat tumbuh sebagai suatu ekspektasi dari ketidakmungkinan dan tak berbeda jauh dengan angan-angan, bersifat maya atau virtual. Ilustrasi dapat hadir dalam berbagai diversifikasi. Bisa melalui tulisan, gambar maupun bunyi (Fariz, 2009). Jenis karakter ilustrasi yang diciptakan untuk memperkuat story dalam game ada dua jenis seperti karakter dua dimensi (2D) dan karakter tiga dimensi (3D). Dari dua jenis karakter tersebut memiliki kelebihan dalam mempengaruhi daya imajinatif seseorang.

\section{(1) Karakter 2D}

Karakter 2D adalah jenis karakter yang memiliki sifat flat secara visual. Bila dilihat dari teknis pembuatannya terdapat dua cara, yaitu manual dan komputer. Dalam Jurnal Segara Widya dengan judul artikel Gaya dan Teknik Perancangan Ilustrasi Tokoh Pada Cerita Rakyat Bali di sebutkan ilustrasi 2D memiliki masing-masing gaya seperti; Kartun, semirealis, realis, seni murni, jepang style, amerika style, kemasan, ubud. Masing-masing memlikiki karakter sendiri dalam mempengarui emosi manusia sesuai dengan penyampaian pesan yang ingin disampaikan.

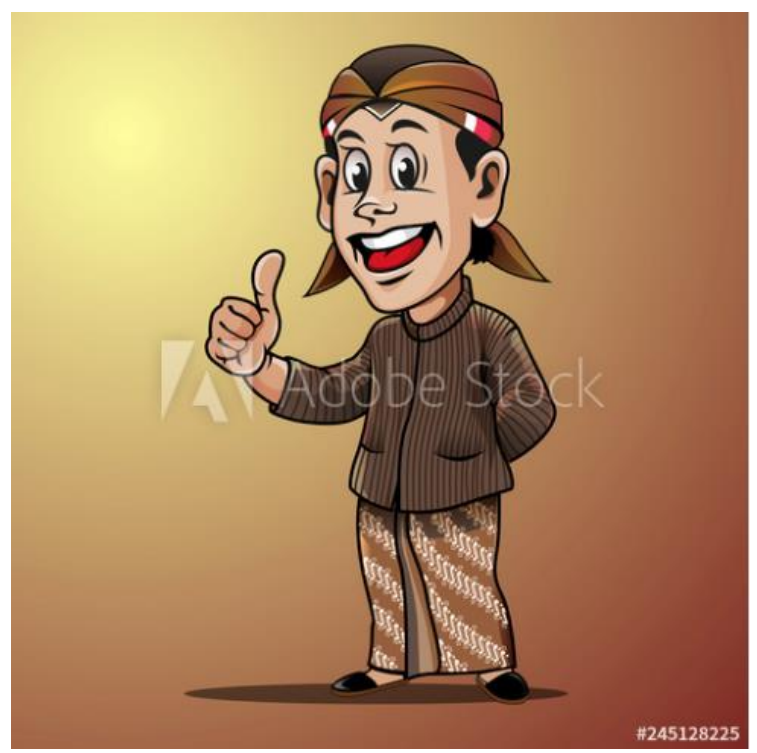

Gambar 1. Gaya Kartun 2D

(Sumber: stock.adobe.com) 


\section{(2) Karakter 3D}

Karakter 3D adalah jenis karakter yang lebih realistis, elemen karakter yang dapat digunakan kembali (reusable). Sementara itu, kekurangan animasi 3D terdapat pada tingginya modal yang diperlukan, seperti dibutuhkan komputer dengan spesifikasi tinggi.

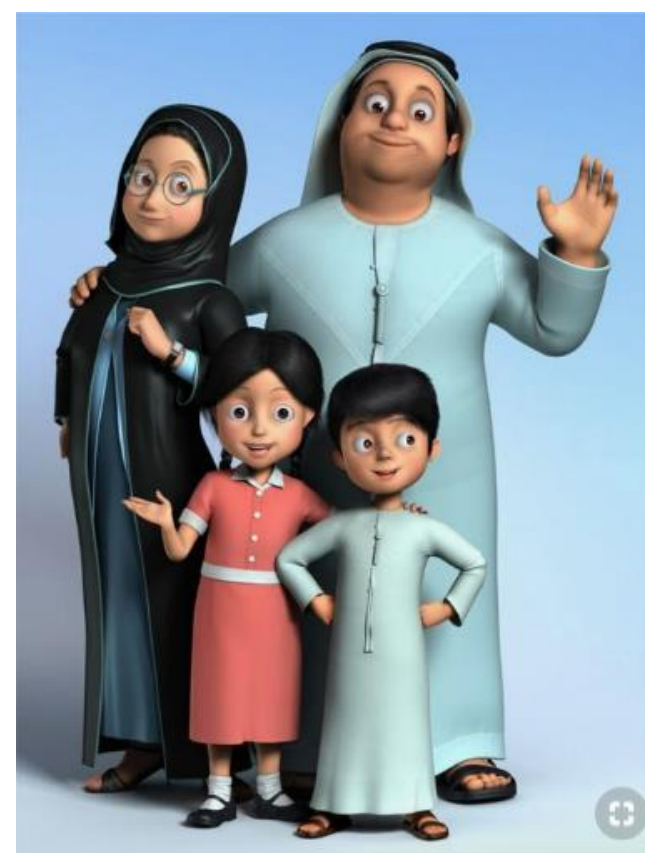

Gambar 2. Gaya Kartun 3D

(Sumber: id.pinterest.com)

\subsubsection{Game Segmentation}

Game Segmentation adalah elemen dalam game yang berpengaruh pada target pemain game. Elemen yang bisa berpengaruh dalam perancangan ilustrasi game terseput. Menurut (Kotler dan Amstong, 1997) segmentasi meliputi: (1) Segmentasi Geografik, adalah pembagian segmentasi seperti negara, regional, negara bagian, kota atau kompleks perumahan. (2) Segmentasi Demografik yaitu pembagian segmentasi menurut umur, jenis kelamin, besar keluarga, siklus kehidupan, pendapatan, pekerjaan, Pendidikan, agama, ras, dan kebangsaan. (3) Segmentasi Psikografik merupakan segmentasi yang terbagi berdasarkan karakteristik social, gaya hidup atau kepribadian.

Dalam perancangan game edukasi segmentasi berpengaruh dalam game yang ingin diciptakan. Keterkaitan soal bahasa, gaya ilustrasi, dan suara yang perlu menjadi bahan pertimbangan dalam memunculkan konsep merancang game edukasi untuk memudahkan penyampaian pesan dalam proses belajar. 


\subsubsection{Teori Proses Belajar}

Proses belajar menurut (Bruner, 2002) menekankan adanya pengaruh kebudayaan terhadap tingkah laku seseorang. Jerome Bruner juga menyebutkan terdapat perkembangan kognitif dalam proses belajar seseorang. Perkembangan kognitif seseorang terjadi melaui tiga tahap pembelajaran yang ditentukan oleh caranya melihat lingkungan, yaitu; tahap enaktif, tahap ikonik, tahap simbolik.

a. Tahap Enaktif

Upaya memahami lingkungan sekitar, artinya dalam memahami proses belajar seseorang, bisa menggunakan pengetahuan motorik, misalnya, melalui sentuhan, pegangan, gerakan, dan sebagainya.

b. Tahap Iconic

Seseorang memahami objek-objek atau proses belajarnya melalui gambar-gambar atau visualisasi verbal. Maksudnya dalam proses belajar sekitarnya seseorang belajar melalui bentuk perumpamaan dan perbandingan (komparasi).

c. Tahap Simbolik

Seseorang telah mampu memilki ide atau gagasan abstrak yang sangat dipengaruhi oleh kemampuannya berbahasa dan logika. Dalam prose belajar sekitarnya seseorang belajar melalui simbol bahasa, logika, matematika dan sebagainya.

\subsubsection{Teori Kebudayaan}

Proses belajar seperti diungkapkan Bruner (2002) menekankan adanya pengaruh kebudayaan terhadap tingkah laku seseorang. Dengan kata lain Kebudayaan bisa membantu proses belajar untuk mempermudah mentrasfer ilmu yang ingin di pelajari seseorang.

Menurut Koentjaraningrat (2000) adanya tiga wujud dari kebudayaan yaitu: (1) Wujud kebudayaan sebagai sebuah kompleks dari ide-ide, gagasan, nilai- nilai, norma-norma, peraturan dan sebagainya. (2) Wujud kebudayaan sebagai suatu kompleks aktivitas serta tindakan berpola dari manusia dalam suatu masyarakat. (3) Wujud kebudayaan sebagai benda-benda hasil karya manusia.

\subsubsection{Batik Indonesia}

Salah satu wujud kebudayaan menurut (Koentjaraningrat, 2000) terdapat wujud bendabenda hasil karya manusia. Dalam hal ini penulis mengambil wujud Batik Indonesia yang begitu banyak ragam motifnyanya. Untuk motif batik yang populer di Indonesia seperti: megamendung, 
tujuh rupa pekalongan, parang rusak, Keraton, priyangan tasikmalaya, lasem, bali, Betawi dan masih banyak yang lain yang kurang begitu populer.

Menurut (Lisbijanto, 2013) bahwa ada 3 jenis batik menurut teknik pembuatannya, yaitu: batik tulis, batik cap dan batik lukis. Perbedaan jenis batik tersebut berdasarkan teknik pengerjaanya dan motif yang ingin dibuat. Karakter ilustrasi batik yang cenderung 2D dapat menjadi bahan pertimbangan dalam merancang game edukasi.

Metode dalam artikel ini menggunakan metode kualitatif-diskriptif dengan memaparkan teori dari ahli dan jurnal yang didiskripsikan dalam paragraf. Untuk penelitian lebih atau perancangan dalam bahasan Game Edukasi dengan Batik bisa menggunakan metodologi Etnografi. Perkembangan media dalam konteks nilai budaya yang kian beragam semakin mengukuhkan eksistensi paradigma kualitatif. Metodologi yang dengan kemampuannya menghasilkan produk analisis yang mendalam selaras dengan data penelitiannya. Menurut Creswell, (2015) etnografi merupakan suatu penelitian kualitatif yang mendeskripsikan dan menafsirkan pola yang sama dari nilai, perilaku, keyakinan, dan bahasa dari suatu kelompok berkebudayaan sama. Metode penelitian Etnografi ini digunakan untuk meneliti nilai falsafah dari batik indonesia dan perilaku target segmentasi game edukasi yang berada di sekolah. Pemaparan kerangka berfikir penulis dalam artikel review Potensi Game Edukasi Dalam Upaya Pelestarian Batik Indonesia dapat tergambar dalam bagan sebagai berikut:

\begin{tabular}{|c|}
\hline Konsep Game \\
$\downarrow$ \\
\hline Game Edukasi \\
\hline$\downarrow$ \\
\hline Karakter Game \\
$\downarrow$ \\
\hline Game Segmentation \\
$\downarrow$ \\
\hline Proses Belajar \\
$\downarrow$ \\
\hline Kebudayaan \\
$\downarrow$ \\
\hline Batik Indonesia \\
$\downarrow$ \\
\hline Pembahasan
\end{tabular}




\subsection{PEMBAHASAN}

Tahap shaping the idea, dalam perancangan game, game edukasi termasuk dalam komponen game yang menjadi style dalam perancangan game. Karakter dalam game edukasi dipengaruhi oleh materi apa yang ingin disampaikan serta segmentasi Geografik, Demografik, Psikografik dalam perancangan dan penyebaran game.

Peran game yang memiliki kelebihan pada visualisasi dari permasalahan nyata dan berhasil dibuktikan bahwa game sangat berguna untuk meningkatkan logika dan pemahaman pemain terhadap suatu masalah melalui proyek game yang dinamai Scratch.

Dalam proses belajar adanya pengaruh kebudayaan terhadap tingkah laku seseorang berpengaruh dalam proses belajar mereka. Bagaimana mengajarkan atau mentransfer ilmu-ilmu kebudayaan dengan cara yang menyenangkan bisa di lakukan dengan merancang game edukasi untuk memudahkan transfer ilmu dari manusia terdahulu ke manusia sekarang.

Batik yang menjadi wujud kebudayaan sebagai benda hasil karya manusia dapat dilestarikan dengan cara dibuatkan game edukasi agar manusia jaman sekarang tidak melupakan sejarah batik Indonesia dan agar tidak diakui negara lain. Pembuatan ilustrasi batik yang cenderung 2D juga dapat digunakan sebagai acuan dalam merancang karakter game edukasi sesuai dengan segmentasi pemain game.

\section{KESIMPULAN}

Dalam simpulan hasil artikel review ini dapat digunakan atau memberikan gambaran konsep yang dapat menjadikan acuan dalam perancangan game edukasi.

a. Game edukasi bisa menjadi potensi media dalam upaya pelestarian batik Indonesia dengan metode pembelajaran yang bisa menyenangkan.

b. Proses belajar manusia dipengaruhi kebudayaan yang dimilikinya serta proses belajarnya bisa melalui gambar-gambar (tahap iconic).

c. Karakter batik indonesia yang cenderung 2D bisa menjadi bahan pertimbangan dalam merancang ilustrasi di game edukasi.

\section{DAFTAR PUSTAKA}

Bruner, Jerome, S. 2007. Discovery Learning at Learning Theories. Retrieved June 10th.

Dillon, Teresa. (2009). Advanture Games for Lerning and Storytelling. UK: Futurelah prototype context paper. Advanture Author 
Fariz, 2009, Living in harmony: Jati Diri, Ketekunan, dan Norma. Jakarta: PT Kompas Media Nusantara

Koentjaraningrat. 2000. Pengantar Ilmu Antropologi. Jakarta : Rineka Cipta

Kotler, Philip dan Gary Armstrong, 2001. Marketing Management, Prenhallindo, Jakarta

Lisbijanto, Herry. 2013. Batik. Yogyakarta: Graha Ilmu

Prensky, Marc. (2012). From Digital Natives to Digital Wisdom. New York.

Rollings, A., Morris, D. (2004). Game Architecture and Desisgn: A New Edition, New Riders Publishing, Indianapolis, Indiana.

$\underline{\text { Referensi dari artikel jurnal: }}$

Nugraheny, Dwi dan Destiranti, Ayuningtias, 2016. Penerapan Edugame Interaktif Untuk Pengenalan Pakaian Adat Nasional Indonesia, Jurnal Angkasa : ISSN 2085-9503

Janottama, I Putu Arya dan Putraka, Agus Ngurah Arya, 2017. Gaya dan Teknik Perancangan Ilustrasi Tokoh pada Cerita Rakyat Bali, Jurnal Segara Widya : ISSN 2354-7154

Referensi dari website:

Clark, R. E. (2006) Evaluating the Learning and Motivation Effects of Serious Games. Rosier school of Education Center for Creative Technologies. Online at: http://projects.ict.usc.edu/itgs/talks/Clark_Serious\%20Games\%20Evaluation.ppt 